\title{
Evaluation of the Counterweight Programme for obesity management in primary care: a starting point for continuous improvement
}

Counterweight Project Team

\begin{abstract}
Background

Evaluation for obesity management in primary care is limited, and successful outcomes are from intensive clinical trials in hospital settings.

Aim

To determine to what extent measures of success seen in intensive clinical trials can be achieved in routine primary care. Primary outcome measures were weight change and percentage of patients achieving $\geq 5 \%$ loss at 12 and 24 months.

\section{Design of study}

Prospective evaluation of a new continuous improvement model for weight management in primary care.

Setting

Primary care, UK.

\section{Method}

Primary care practice nurses from 65 UK general practices delivered interventions to 1906 patients with body mass index $(\mathrm{BMI}) \geq 30 \mathrm{~kg} / \mathrm{m}^{2}$ or $\geq 28 \mathrm{~kg} / \mathrm{m}^{2}$ with obesity-related comorbidities.

Results

Mean baseline weight was $101.2 \mathrm{~kg}$ (BMI $37.1 \mathrm{~kg} / \mathrm{m}^{2}$ ); $25 \%$ of patients had $\mathrm{BMI} \geq 40 \mathrm{~kg} / \mathrm{m}^{2}$ and $74 \%$ had $\geq 1$ major obesity-related comorbidity. At final data capture 1419 patients were in the programme for $\geq 12$ months, and 825 for $\geq 24$ months. Mean weight change in those who attended and had data at 12 months $(n=642)$ was $-3.0 \mathrm{~kg}(95 \% \mathrm{Cl}=-3.5$ to $-2.4 \mathrm{~kg})$ and at 24 months $(n=357)$ was $-2.3 \mathrm{~kg}(95 \% \mathrm{Cl}=-3.2$ to $-1.4 \mathrm{~kg}$ ). Among attenders at specific time-points, $30.7 \%$ had maintained weight loss of $\geq 5 \%$ at 12 months, and $31.9 \%$ at 24 months. A total of 761 (54\%) of all 1419 patients who had been enrolled in the programme for $>12$ months provided data at or beyond 12 months.
\end{abstract}

\section{Conclusion}

This intervention achieves and maintains clinically valuable weight loss within routine primary care.

Keywords

continuous improvement; lifestyle intervention; primary care; weight loss maintenance; weight management.

\section{INTRODUCTION}

Obesity is a major public health risk, presenting a burden of obesity-related disease, ${ }^{1}$ impaired quality of life, ${ }^{2}$ and implications for medical care expenditure. $^{3}$ Obese populations attend general practice frequently, ${ }^{4}$ incurring increased prescribing costs. ${ }^{5}$ Almost one-quarter of all UK adults are now obese, ${ }^{6,7}$ and obese people with no intervention will steadily gain further weight over time. ${ }^{8}$

Lifestyle intervention with modest weight loss of $5-10 \%$ reduces progression to diabetes by up to $58 \%$ over 4 years. ${ }^{9,10}$ Multiple clinical benefits result, including reductions in risk of cardiovascular disease. ${ }^{11,12}$

Despite clinical guidelines for obesity management ${ }^{11,13}$ and related disease,${ }^{14}$ there is little evidence from primary care. Lack of evidence, time, and training are barriers to addressing weight in primary care. ${ }^{15}$ Isolated weight management training for practitioners does not result in patient weight loss. ${ }^{16}$

This paper presents final outcomes from a 5-year evaluation phase of the Counterweight Programme for obesity management in routine general practice. Programme methodology and preliminary outcomes have been published previously. ${ }^{17,18}$

Writing team ${ }^{*}$ : HM Ross, PGDipDiet, RD, honorary reader in nutrition \& dietetics, and national coordinator Counterweight Programme, The Robert Gordon University, Aberdeen. R Laws, MSc (Nutrition \& Dietetics) RD, Nutrition \& Dietetic Service; $J$ Reckless, DSc, MD, FRCP, honorary reader in medicine and consultant endocrinologist, University of Bath and Royal United Hospital, Bath. M Lean, MA, MD, FRCP, FRCPS, professor in human nutrition and consultant physician, Department of Human Nutrition, University of Glasgow and Royal Infirmary, Glasgow. ${ }^{*}$ List of authors at end of article.

Address for correspondence

Dr John Reckless, Department of Endocrinology, Royal United Hospital, Combe Park, Bath, BA1 3NG. E-mail: mpsjpdr@bath.ac.uk

Submitted: 31 January 2008; Editor's response: 31 March 2008; final acceptance: 30 June 2008.

(c)British Journal of General Practice 2008; 58: 548-554.

DOI: 10.3399/bjgp08X319710 


\section{METHOD}

\section{Design}

The Counterweight Programme was a prospective, evidence- and theory-based intervention for weight management, evaluated in 65 general practices from seven UK regions. Counterweight is a model of continuous improvement. The programme was conducted in a in a naturalistic, primary care setting which is close to the patient's own environment, ${ }^{19,20}$ with 'closed-loop' audit of outcomes allowing programme refinement.

Practices that reflected UK profiles, varying in size, location, and category of social deprivation, were invited to participate. When Counterweight was established there was no evaluated model for weight management in primary care. A cluster randomisation model including a deferred intervention would have had limitations, because data collection could have an intervention effect. A within-practice experimental design with a control group was not possible, as Counterweight works with the whole practice team.

\section{Practice intervention}

Weight management advisers, all registered dietitians with specialist postgraduate training and experience in obesity management, led and facilitated implementation of the programme. They offered expertise in obesity management and provided protocols and training materials for practice staff and patient education materials. ${ }^{17}$ One-hour of training was provided for GPs, which included review of Counterweight screening and treatment pathways, importance of raising the issue of weight with patients, and review of the benefits of a 5-10\% weight loss for patients with obesity.

An 8-hour training programme was provided for practice nurses. Practice nurses incorporated the programme into appointments which were usually spent managing comorbid conditions. Practices were not asked to set up additional clinics for weight management, although some did.

Peer support in the practice was provided once or twice each month by the weight management adviser until practice nurses achieved competency ${ }^{17}$ and confidence. Mentoring usually took 6 months. Subsequent visits by weight management advisers were to assist with auditing outcomes, provision of materials (for example, information leaflets), and training of new staff members.

The practice nurse role was to deliver patient education through discussion about weight management, communication of information, and the transfer of behaviour change skills and strategies during weight-management sessions. In several practices healthcare assistants took on this role. Weight management advisers conducted patient

\section{How this fits in}

The personal, societal, and healthcare costs of obesity are of widespread

concern. Despite evidence-based clinical guidelines for components of obesity management, translation to general practice has lacked evaluation. This study demonstrates that if practice nurses are given training on a structured

programme, are mentored within clinical practice, and results are continuously audited, they can achieve and maintain clinically beneficial weight loss in their patients with obesity.

consultations only during training of practice nurses. The unique feature of this programme was the mentoring provided by the weight management advisers in routine clinical settings.

\section{Patient intervention}

Patients were identified for the Counterweight Programme by GPs and practice nurses during normal appointments. Practice nurses targeted patients aged

Table 1. Baseline characteristics for eligible patients enrolled in the Counterweight Programme at time of analysis.

\begin{tabular}{|c|c|c|c|}
\hline & All & $\begin{array}{l}\text { Eligible for 12- } \\
\text { month follow-up }\end{array}$ & $\begin{array}{l}\text { Eligible for } 24- \\
\text { month follow-up }\end{array}$ \\
\hline Patients enrolled, $n$ & 1906 & 1419 & 825 \\
\hline Age in years, mean (SD) & $49.4(13.5)$ & $49.9(13.6)$ & $50.4(13.7)$ \\
\hline Females, $n(\%)$ & $1468(77.0)$ & $1070(75.4)$ & $616(74.7)$ \\
\hline Males, $n(\%)$ & $438(23.0)$ & $349(24.6)$ & $209(25.3)$ \\
\hline BMI kg/m², mean (SD) & $37.1(6.0)$ & $37.0(6.1)$ & $37.1(5.6)$ \\
\hline $\mathrm{BMI} \geq 40 \mathrm{~kg} / \mathrm{m}^{2}, n(\%)$ & $485(25.4)$ & $355(25.0)$ & $213(25.8)$ \\
\hline Diabetes present, $n(\%)$ & $258(13.5)$ & $202(14.2)$ & $127(15.4)$ \\
\hline Impaired fasting glucose ${ }^{\mathrm{a}}, n(\%)$ & 119/1205 (9.9) & 97/891 (10.9) & $59 / 536(11.0)$ \\
\hline Cardiovascular disease $^{\mathrm{b}}, n(\%)$ & $152(8.0)$ & $117(8.2)$ & $71(8.6)$ \\
\hline Hypertension, $n$ (\%) & $612(32.1)$ & $469(33.1)$ & $265(32.1)$ \\
\hline $\begin{array}{l}\text { Hypertension or raised } \\
\text { blood pressure }, n(\%)\end{array}$ & $1153(60.5)$ & $873(61.5)$ & $512(62.1)$ \\
\hline Hyperlipidaemia, $n$ (\%) & $239(12.5)$ & $187(13.2)$ & $120(14.5)$ \\
\hline $\begin{array}{l}\text { Hyperlipidaemia or raised } \\
\text { total cholesterol }{ }^{\mathrm{d}}, n(\%)\end{array}$ & $958(50.3)$ & $725(51.1)$ & $436(52.8)$ \\
\hline Comorbidity $^{e} \geq 1, n(\%)$ & 1408 (73.9) & 1069 (75.3) & $628(76.1)$ \\
\hline Comorbidity $^{e} \geq 2, n(\%)$ & $916(48.1)$ & $711(50.1)$ & $413(50.1)$ \\
\hline Comorbidity $^{e} \geq 3, n(\%)$ & $533(28.0)$ & $415(29.2)$ & $240(29.1)$ \\
\hline Ex-smoker, $n(\%)$ & $575 / 1852(30.2)$ & 453/1380 (31.9) & $253 / 804(31.5)$ \\
\hline Practice in affluent area ${ }^{\dagger}, n(\%)$ & $651(34.2)$ & $477(33.6)$ & $267(32.4)$ \\
\hline $\begin{array}{l}\text { Practice in intermediate } \\
\text { deprivation area }, n(\%)\end{array}$ & $562(29.5)$ & $425(30.0)$ & $265(32.1)$ \\
\hline Practice in deprived area ${ }^{f}, n(\%)$ & $693(36.4)$ & $517(36.4)$ & $293(35.5)$ \\
\hline \multicolumn{4}{|c|}{ 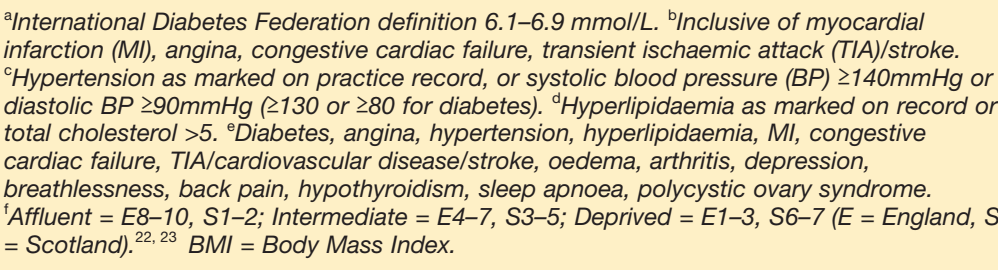 } \\
\hline
\end{tabular}




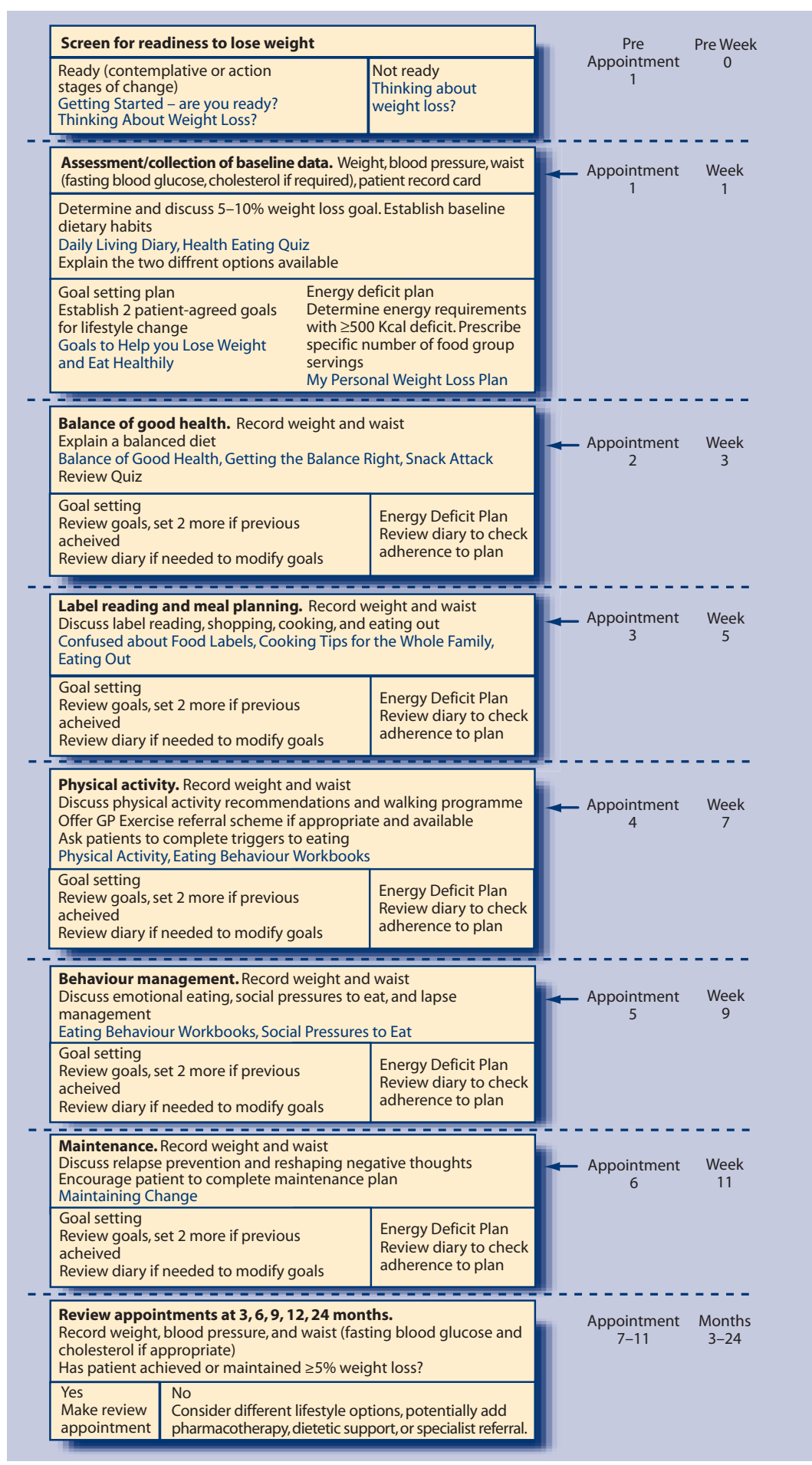

Figure 1. Counterweight Programme intervention. Patient education booklets are shown in blue (two other patient booklets are available: Advice for Patients taking Orlistat, and Advice for Patients taking Sibutramine).
$18-75$ years with body mass index $(\mathrm{BMI}) \geq 30 \mathrm{~kg} / \mathrm{m}^{2}$ or $\geq 28 \mathrm{~kg} / \mathrm{m}^{2}$ with obesity-related comorbidities (Table 1).

In line with the transtheoretical model of behaviour change, patients were offered interventions tailored to their stage of change. ${ }^{21}$ Individuals in the contemplative or action stages of change were offered the Counterweight Programme (Figure 1), and those considered not ready to change were provided with information about the benefits of $5-10 \%$ weight loss and encouraged to consider assistance in the future.
Obesity-related cardiovascular disease risk factors were assessed, and comorbidities were recorded from primary care records.

First-line interventions were a prescribed-eating plan, a goal-setting approach, or a group intervention (exclusively based on goal setting). These were all aimed at achieving an energy deficit of $\geq 500 \mathrm{kcal} /$ day. Practice nurse feedback suggested that their knowledge, skills, and confidence influenced whether they offered group intervention, as did availability of a suitable venue.

As patients progressed through the Counterweight Programme, emphasis was increasingly placed on weight maintenance and prevention of regain. Patients were asked to commit to nine appointments in 12 months after initial screening. This included six individual appointments (10-30 minutes each) or six group sessions ( 1 hour each) over a 3-month period, and then follow-up at 6, 9, 12, 24 months (Figure 1) . A 3-month review was generally included in session 6 of the intervention, but could take place outside this appointment.

Patients were eligible to be considered for pharmacotherapy if they did not achieve $\geq 5 \%$ weight loss at 3 months. Letters and flags on the practice computer system (onscreen alerts of when patients were due an appointment with Counterweight) were used to assist patient recall at 12 and 24 months. Recruitment was continuous and data capture for the evaluation presented in this paper was from 1 January 2001 to 31 December 2004.

Outcome data were recorded on a dedicated Counterweight patient record card and transferred to a central database for analysis. Primary outcome measures were weight change at 12 and 24 months and percentage of patients achieving and maintaining $\geq 5 \%$ loss at these time points. Secondary outcomes were changes at 12 months in blood pressure, total cholesterol, high-density lipoprotein cholesterol, and blood glucose and glycated haemoglobin ( $\mathrm{HbA} 1$; diabetic patients only). The aim of collecting secondary outcome data was to assess whether data followed expected well-documented trends in line with associated weight management, ${ }^{10,11}$ rather than to assess the impact of weight change. A data set of investigations related to secondary consequences of obesity was recommended and collected in line with local guidelines and policies. Counterweight aimed to improve identification and management of secondary diseases, such as diabetes and hypertension, including the use of appropriate medications.

Category of social deprivation was measured according to practice location by using the Carstairs Index (Scotland), ${ }^{22}$ and the Jarman Index (England). ${ }^{23}$ It was recognised that this would not necessarily reflect individual patient status but was expected to reflect the 
practice profile very broadly. In England $(E)$ affluence is split into 10 categories, with category one being the most deprived; while in Scotland (S) there are seven categories, with seven being the most deprived. As scales and bandings differ the following aggregates were used: affluent $=$ E8-10, S1-2, intermediate = E4-7,S3-5, and deprived = E1-3, S6-7.

Various data were reported to practices biannually for numbers enrolled and attending for follow-up of weight, BMI, and risk-factor changes; this information was compared to other anonymised practices, regionally and nationally. No additional incentive (other than reporting outcomes back to practices) was offered to practices for data measurement and recording.

\section{Statistical analysis}

Mean weight change from baseline was compared using paired $t$-tests. Confidence intervals (Cls) for patient proportions who lost $\geq 5 \%$ of initial weight were calculated using Confidence Interval Analysis software (version 2.1.2). All other statistical package analyses were performed using SPSS (version 15.0).

\section{RESULTS}

Of 65 practices agreeing to participate in the Counterweight Programme, 56 participated. Nine practices did not enrol patients due to nurses leaving their positions, maternity leave, and competing practice priorities. In the 56 practices, activity patterns varied: 34 practices were continuing to enrol new patients into the programme 12 months after the programme had started; 10 practices enrolled $\geq 60$ patients over 12 months; 17 practices enrolled $\geq 40$ patients over 12 months; and the remaining 29 practices enrolled $<40$ patients over 12 months. Twenty-two practices from deprived areas, 22 from intermediately-deprived areas, and 12 practices from affluent areas contributed $36.4 \%, 29.5 \%$, and $34.2 \%$ of patients respectively.

The 56 practices identified 2095 patients, of which 1906 satisfied eligibility criteria. At data-set closure, 1419 patients had reached $\geq 12$ months, and 825 had reached 24 months. Data were available for 642 of
Table 2. Change in weight and body mass index (BMI) from baseline in 1419 patients enrolled for at least 12 months.

\begin{tabular}{lccccc}
$\begin{array}{l}\text { Follow-up } \\
\begin{array}{l}\text { attendance } \\
\text { (months) }\end{array}\end{array}$ & Attenders, $n$ & $\begin{array}{l}\text { Mean (SD) } \\
\text { weight } \\
\text { change, } \mathrm{kg}\end{array}$ & $95 \% \mathrm{Cl}$ & $\begin{array}{c}\text { Mean (SD) } \\
\mathrm{BMl} \text { change, } \\
\mathrm{kg} / \mathrm{m}^{2}\end{array}$ & $95 \% \mathrm{Cl}$ \\
\hline 0 & 1419 & - & - & - & - \\
\hline 3 & 775 & $-3.34(3.53)$ & -3.59 to -3.09 & $-1.22(1.28)$ & -1.32 to -1.13 \\
\hline 6 & 548 & $-4.24(5.19)$ & -4.68 to -3.80 & $-1.55(1.88)$ & -1.71 to -1.39 \\
\hline 12 & 642 & $-2.96(6.64)$ & -3.47 to -2.44 & $-1.08(2.41)$ & -1.27 to -0.89 \\
\hline
\end{tabular}

1419 patients at 12 months, and for 357 of 825 at 24 months; the remainder did not reach these datacollection time-points. Baseline data are presented for all 1906 enrolled patients, together with results at $3,6,12$, and 24 months. As some patients missed one or more appointments or dropped out, mean weight changes reflect a patient sub-group of those who attended, comprising different individuals at different time-points.

\section{Patient characteristics}

Mean age for 1906 patients at baseline was 49.4 years (SD 13.5 years, range 18.1-76.0 years); $77 \%$ were female; and, of those enrolled in the programme, obesity was severe (mean weight $101.1 \mathrm{~kg}$, BMI $37.1 \mathrm{~kg} / \mathrm{m}^{2}$ ). Nearly three-quarters of patients had $\geq 1$, nearly half $\geq 2$, and over a quarter $\geq 3$ obesity-related comorbidities (Table 1).

\section{Weight changes}

Weight changes at 12 months ranged from $+17.5 \mathrm{~kg}$ to $-34.9 \mathrm{~kg}$. Of patients attending at 12 months $(n=642)$, mean weight change was approximately $-3.0 \mathrm{~kg}(95 \%$ $\mathrm{Cl}=-3.5$ to -2.4 ; Table 2). Mean change in BMl at 12 months was $-1.1 \mathrm{~kg} / \mathrm{m}^{2}(95 \% \mathrm{Cl}=-1.3$ to -0.9$)$, with $30.7 \%$ of $12-$ month attenders (13.9\% of all patients) maintaining $\geq 5 \%$ weight loss (Tables 2 and 3 ). Of patients attending at 24 months, mean weight change was $-2.3 \mathrm{~kg}(95 \% \mathrm{Cl}=-3.2$ to $1.4, n=357 / 825)$ with $31.9 \%$ of 24 -month attenders $(13.8 \%$ of all 825 patients) known to have lost $\geq 5 \%$ of their initial weight.

A further 119 patients who missed the 12-month time-point returned at 24 months when they had a

Table 3. Data from attenders at the 12-month time-point, as a proportion of attenders and as a proportion of all 1419 patients who had been enrolled for at least 12 months, who had lost $\geq 5 \%$ of their initial weight.

Proportion of attenders at specific time-points

Proportion of all patients who were enrolled for at least 12 months

\begin{tabular}{|c|c|c|c|c|c|c|}
\hline Months & Attenders, $n$ & $\begin{array}{c}\text { Lost } \geq 5 \% \text { : } \\
\%, 95 \% \mathrm{Cl}(n)\end{array}$ & $\begin{array}{c}\text { Not lost } \geq 5 \% \text { : } \\
\%(n)\end{array}$ & $\begin{array}{c}\text { Lost } \geq 5 \%: \\
\%, 95 \% \mathrm{Cl}(n)\end{array}$ & $\begin{array}{c}\text { Not lost } \geq 5 \% \text { : } \\
\%\end{array}$ & $\begin{array}{c}\text { Not known } \\
\%(n)\end{array}$ \\
\hline 0 & 1419 & - & - & - & - & - \\
\hline 3 & 775 & $26.1,23.1$ to 29.3 (202) & 73.9 (573) & $14.2,12.5$ to $16.2(202)$ & 40.4 & $45.4(644)$ \\
\hline 6 & 548 & $38.0,34.0$ to 42.1 (208) & $62.0(340)$ & $14.7,12.9$ to 16.6 (209) & 24.0 & $61.4(871)$ \\
\hline 12 & 642 & $30.7,27.2$ to $34.4(197)$ & $69.3(445)$ & $13.9,12.2$ to 15.8 (197) & 31.4 & $54.8(777)$ \\
\hline
\end{tabular}

Not included above are a further 119 patients who missed the 12-month time-point but returned at 24 months when they had a mean weight change of -1.4 kg. 
Table 4. Factors affecting weight loss in patients who attended for data collection at 12 months $(n=642)$.

\begin{tabular}{lccc}
\multicolumn{3}{c}{ Mean (SD) weight } \\
& $n$ & change, kg & 95\% Cl \\
\hline Age, years & & & \\
$<25$ & 21 & $-1.69(6.93)$ & -4.84 to -1.47 \\
$25-34$ & 55 & $-2.25(8.07)$ & -4.43 to -0.07 \\
$35-44$ & 121 & $-4.18(8.69)$ & -5.75 to -2.62 \\
$45-54$ & 139 & $-2.82(6.45)$ & -3.90 to -1.74 \\
$55-64$ & 173 & $-2.79(5.87)$ & -3.67 to -1.91 \\
$\geq 65$ & 133 & $-2.71(4.58)$ & -3.50 to -1.92 \\
\hline Sex & & & \\
Male & 171 & $-3.40(7.31)$ & -4.50 to -2.30 \\
Female & 471 & $-2.80(6.38)$ & -3.38 to -2.22 \\
\hline Baseline BMI, kg/m² & & & \\
28 to $<30$ & 28 & $-1.87(4.96)$ & -3.80 to -0.05 \\
30 to $<35$ & 244 & $-2.02(4.89)$ & -2.64 to -1.41 \\
35 to $<40$ & 210 & $-2.94(6.42)$ & -3.81 to -2.06 \\
$\geq 40$ & 160 & $-4.60(8.86)$ & -5.98 to -3.22 \\
\hline Diabetes & & & \\
Not present & 510 & $-3.30(6.98)$ & -3.91 to -2.70 \\
Present & 132 & $-1.63(4.91)$ & -2.47 to -0.78 \\
\hline Arthritis & & & \\
Not present & 482 & $-3.07(6.86)$ & -3.68 to -2.46 \\
Present & 160 & $-2.62(5.94)$ & -3.55 to -1.70 \\
\hline Visits in 12 months & & \\
$0-5$ & 212 & $-0.65(5.37)$ & -1.38 to -0.07 \\
$6-9$ & 200 & $-2.60(6.06)$ & -3.45 to -1.76 \\
$10-15$ & 148 & $-4.67(6.13)$ & -5.66 to -3.67 \\
$16-20$ & 49 & $-5.95(6.74)$ & -7.88 to -4.01 \\
$>21$ & 33 & $-7.82(11.62)$ & -11.94 to -3.70 \\
\hline
\end{tabular}

astratum-specific mean weight losses. Patients in each stratum (as with the whole group) on average lost weight. No confidence intervals included the null value of $O \mathrm{~kg}$. $B M I=$ body mass index .

mean weight change of $-1.4 \mathrm{~kg}$. Patients known to remain in Counterweight for $\geq 12$ months $(642+119$ $=761$ ) accounted for $54 \%$ of 1419 enrolled.

Weight change data reflect outcomes from a variety of specific treatments. ${ }^{17}$ Seventy per cent of patients attending at 12 months received individual lifestyle interventions (prescribed eating plan or goal setting), 34\% attended a group intervention (some patients had individual and group intervention), and $19 \%$ received anti-obesity drugs at some point. Some patients received a combination of interventions at the same time. Patients attending session 6 of the intervention programme received specific weight loss maintenance advice; $13 \%$ of those attending at 12 months were recorded as having received specific weight-loss maintenance advice as well as weight-loss advice.

\section{Factors associated with weight change}

Some factors were associated with greater mean weight loss at 12 months (Table 4). Males lost an average of $3.4 \mathrm{~kg}$ whereas females lost an average of $2.8 \mathrm{~kg}$. Their $95 \% \mathrm{Cls}$ overlap, suggesting that the observed difference did not reach statistical significance. The number of visits for Counterweight appeared to be associated with greater mean weight loss. Ages 35-44 years, higher baseline BMI, and absence of diabetes or arthritis were also associated with increased mean weight loss (Table 4).

\section{Secondary endpoints}

Mean secondary endpoint changes in all patients with 12-month data were: total-cholesterol $-0.29 \mathrm{mmol} / \mathrm{L} \quad(n=303, P<0.001)$; low-density lipoprotein cholesterol $-0.35 \mathrm{mmol} / \mathrm{L} \quad(n=172$, $P<0.001)$; HDL-cholesterol $+0.03 \mathrm{mmol} / \mathrm{L}(n=234, P$ $=0.08)$; systolic blood pressure $-2.03 \mathrm{mmHg}(n=$ $580, P=0.01$ ); diastolic blood pressure $-1.15 \mathrm{mmHg}$ ( $n=580, P=0.01$ ), and (in patients with diabetes only) HbA1c $-0.19 \%(n=93, P=0.17)$; and fasting glucose $+0.08 \mathrm{mmol} / \mathrm{L}$ ( $n=28$, non-significant).

\section{DISCUSSION}

\section{Summary of main findings}

This study presents, for the first time, prospective evidence of an effective model of weight management for primary care. Of the practices that initially agreed to implement Counterweight, $86 \%$ became active, and weight change data compare favourably with those achieved in specialist research settings. ${ }^{9}$ Despite no extra practice funding, more than two-thirds of practices enrolled new patients beyond 12 months, allocating time previously spent managing obesity somewhat haphazardly. Almost half of all patients attended 12-month follow-up. The most favourable results were seen in high attenders, suggesting that processes to optimise attendance and retention are worthy of further investigation.

\section{Strengths and limitations of the study}

Key features of the Counterweight Programme include its naturalistic setting within routine primary care, its realistic evaluation on outcomes and process, and its scope for 'closed-loop audit'. Continuous improvement methodology, using various experimental, observational, and qualitative research methods, is increasingly recognised as potentially providing cheaper, quicker, tailored improvements to services than randomised trials.

Practice nurses valued the opportunity to be trained to practise more effectively in an area which affects so much of their day-to-day work. At a wider practice level, provision of feedback data on practice performance was appreciated and provided an incentive to continue implementing the programme. Introduction of a new contract for general practice with few points linked to obesity management led some practices to withdraw from the programme. This may threaten practicebased weight management in the future. 
Having no control group prevents exact quantification of the Counterweight Programme achievement, but a mean weight loss of $2-3 \mathrm{~kg}$ in patients similar to those who underwent the programme is improbable without intervention. ${ }^{8}$ Outside a formal, heavily-funded research setting it was not considered feasible to make detailed evaluations of obesity-related disease markers or risk factors, again preventing documentation of the exact impact of Counterweight on secondary outcomes.

Evaluating attrition rates is difficult in weight management because patients often attend and adhere intermittently. The attrition rate in Counterweight is consistent with another evaluation of lifestyle intervention. ${ }^{11}$ Apparently high drop-out rates at specific time-points can exaggerate patient programme losses.

Less than one-quarter of patients was male, despite practice nurses often working within comorbidity clinics where more males might be expected. Females are more likely than males to have weight ever recorded on practice computer systems, ${ }^{24}$ and females attend primary care more frequently than males. Sex differences in BMl screening may influence recommendations for intervention. In view of risk from comorbidities, strategies need to be developed to engage males to participate in weight management, perhaps targeting them through local advertising, wellmen clinics, and opportunistically at unrelated appointments.

\section{Comparison with existing literature}

Counterweight was a large intervention in general practice, with results that compare favourably with lifestyle arms of heavily-resourced, randomised, controlled, weight-loss trials in specialist clinical settings. The US National Institutes of Health review found a net mean weight change at 12 months of $-3.3 \mathrm{~kg}$ in 29 randomised controlled trials. ${ }^{11}$ The diet and exercise arm of the trial by the Diabetes Prevention Program Research Group achieved >5\% weight loss for $58 \%$ of participants. ${ }^{9}$

Counterweight programme has been used for patients identified with obesity-related conditions. Not all changes in risk factors can be attributed to weight change. Patients in Counterweight may have had improved identification and optimised treatment of co-existing cardiovascular risk factors as part of their care, in keeping with guidelines for overall aims of improving weight management. ${ }^{11}$

Expectations and aspirations of both patients and practitioners in obesity treatment are often unrealistic, impacting on perceived success at individual and service levels: $5-10 \%$ weight loss carries major medical benefits. ${ }^{9,25}$ Against usual patterns of $\sim 1 \mathrm{~kg} /$ year weight-gain, ${ }^{8}$ a maintained weight loss of $\sim 5 \%$ is associated with substantial intra-abdominal fat loss, ${ }^{26}$ and significant prevention or amelioration of comorbidities, particularly cardiovascular and metabolic risks. Counterweight training emphasises the medical benefits of a $5-10 \%$ weight loss and maintenance, and encourages better alignment of patient expectations with this success criterion.

\section{Implications for clinical practice}

This study suggests that practice nurses can achieve and maintain clinically beneficial patient weight loss. Adopting this model of continuous improvement within primary care will provide the best evidencebased programme, and provide frameworks to develop and evaluate new or refined methods for weight management. Health economic analysis using the obesity model of the National Institute for Health and Clinical Excellence ${ }^{27}$ suggests the programme is cost-effective, ${ }^{28}$ and dominant (costsaving) compared with no intervention. ${ }^{29}$

After completion of the 5-year evaluation programme, materials were reviewed, revised, and more clearly linked; lapse management has been moved from session 5 to session 1, and more structured systems have been introduced to assist patient recall. An additional nurse training session focuses on consolidation of learning and weight-loss maintenance. Local dietitians are now trained by Counterweight weight-management advisers to enable long-term sustainability.

\section{Funding body}

Roche Products Ltd provided an initial 6-year unencumbered educational grant-in-aid to the Counterweight Project Board and to Robert Gordon's University, Aberdeen. Roche Products Ltd had no input to the design and conduct of the study; nor to collection, management, analysis, and interpretation of the data; and nor to preparation, review, or approval of the manuscript. The programme was designed and run by the Counterweight Project Team independent of Roche Products Ltd. Since completion of the evaluation phase in 2005, the Scottish Government has funded the Counterweight Programme. In England individual Primary Care Trusts commission the programme. No commercial organisation has any ongoing interest in the Counterweight Programme. The Weight Management Adviser team is employed by the Robert Gordon University, and central data collection and analyses are managed by Glasgow University. There is a Counterweight website: www.counterweight.org

\section{Ethical approval}

The Counterweight Programme was approved by the UK West Midlands Multi-Centre Research Ethics Committee (UK 99/07/74) and subsequently by Local Research Ethics Committees in each area

\section{Competing interests}

$\mathrm{MM},{ }^{3} \mathrm{JB},{ }^{1-5} \mathrm{RAL}^{3}{ }^{3} \mathrm{JPDR},{ }^{1,3-5} \mathrm{PAN},{ }^{3} \mathrm{SK},{ }^{1-3}$ ELMCC $,{ }^{3} \mathrm{MEJL},{ }^{1-5}$ GFL, ${ }^{3} \mathrm{GSF},{ }^{5} \mathrm{MFQ},{ }^{3} \mathrm{JHB},{ }^{1-4} \mathrm{SMH},{ }^{3} \mathrm{NF}^{1-5}{ }^{1-5} \mathrm{WH},{ }^{1-4} \mathrm{HMR},{ }^{3,6}$ $\mathrm{DJH},{ }^{5} \mathrm{SR},{ }^{5} \mathrm{DSM},{ }^{5} \mathrm{BS}^{5}$ declare potential competing interests: ${ }^{1}$ Have acted as consultants. ${ }^{2}$ Have received lecture honoraria. ${ }^{3} \mathrm{H}$ ave attended national/international meetings as guests of Roche Products Ltd. ${ }^{4}$ Involvement as above with other pharmaceutical companies with an interest in obesity. ${ }^{5}$ Research grant. ${ }^{6} \mathrm{HMR}$ was employed by Roche Products Ltd 2000-2007 but reported and was responsible to the Chair of the Counterweight Project Team. HMR was 
employed by the Robert Gordon University from 2007. The programme national coordinator was employed by the sponsor, but reported, and was responsible, to the Chair of the Counterweight Project Team. All intellectual property rights reside with the Counterweight Project Team

\section{Acknowledgements}

We are grateful to the Counterweight practices for their enthusiasm and cooperation, and to all the patients who participated. Thanks go to Dr J Wilding and Professor A Barnett who participated in the initial discussions in the development of Counterweight, to Helen Gibbs (3 years) and to Jenny Brown (4 years) who worked as weight management advisers, and to Ross Morton, data analyst from Glasgow West of Scotland Cancer Surveillance Unit who contributed to data analyses

\section{Authors}

The principle investigators in each centre are members of the project board and led the study design. Weight management advisors: Maria McQuigg, MSc (Health Promotion and Health Education) RD, Clinical Research Unit, Grampian University Hospitals Trust, Aberdeen; Rachel Laws, MSc (Nutrition \& Dietetics) RD, Nutrition \& Dietetic Service, Royal United Hospital, Bath; Paula Noble, PGDipDiet, DMS, RD, University of Warwick, University Hospitals Coventry \& Warwickshire NHS Trust, Coventry; Louise McCombie, PGDipDiet, RD, Department of Human Nutrition, Glasgow Royal Infirmary, Glasgow; Felicity Lyons, PGDipDiet, RD, Nutrition \& Dietetic Research Group, Hammersmith Hospitals NHS Trust, London; Sarika Mongia, BSc, PGDipDiet, RD, Nutrition \& Dietetic Research Group, Hammersmith Hospitals NHS Trust, London; Marney Quinn, BSc Hons (Nutrition \& Dietetics) RD, Leeds General Infirmary, Leeds; Sarah Haynes, PGDipDiet, PGDipHealthSci, RD, Wellcome Clinical Research Facility, Addenbrooke's Hospitals, Cambridge. Principal investigators: John I Broom, FRCP, FRCPath, research professor and consultant in clinical biochemistry \& metabolic medicine, The Robert Gordon University, Aberdeen; John Reckless, DSc $\mathrm{MD}$, FRCP, honorary reader in medicine and consultant endocrinologist, University of Bath and Royal United Hospital, Bath; Sudhesh Kumar, MD, FRCP, professor of medicine, diabetes and metabolism and honorary consultant, University of Warwick, University Hospitals Coventry \& Warwickshire NHS Trust, Coventry; Michael Lean, MA, MD, FRCP, FRCPS, professor in human nutrition and consultant, physician, Department of Human Nutrition, University of Glasgow and Royal Infirmary, Glasgow; Gary Frost, PhD, RD, head of the Nutrition and Dietetic Research Group, Imperial College Hammersmith Campus, London; Julian $\mathrm{H}$ Barth, MD, FRCP, FRCPath, consultant in chemical pathology \& metabolic medicine, Leeds Teaching Hospitals, NHS Trust, Leeds; Nick Finer, FRCP, clinical director, Wellcome Clinical Research Facility, Addenbrooke's Hospitals, Cambridge. GPs: David W Haslam, MBBS, DGM, GP principal, National Obesity Forum, Nottingham. Counterweight project coordinator: Hazel $M$ Ross, PGDipDiet, RD, honorary reader in nutrition \& dietetics, and national coordinator Counterweight Programme, The Robert Gordon University, Aberdeen and Roche Products Ltd, Welwyn Garden City. Data and statistical analysis: the late David Hole, MSc, FFPHM, professor, Public Health and Health Policy, Division of Community Based Sciences, University of Glasgow, Glasgow; Steven Radziwonik, BSc Hons (Statistics), Public Health and Health Policy, Division of Community Based Sciences, University of Glasgow, Glasgow; David S Morrison, $\mathrm{MRCPI}, \mathrm{MPH}, \mathrm{FFPH}$, clinical senior lecturer in cance epidemiology, Public Health and Health Policy, Division of Community Based Sciences, University of Glasgow, Glasgow; Billy Sloan, BSc, data development manager, Public Health and Health Policy, Division of Community Based Sciences, University of Glasgow, Glasgow. All contributors reviewed and contributed to the final manuscript.

\section{Discuss this article}

Contribute and read comments about this article on the Discussion Forum: http://www.rcgp.org.uk/bjgp-discuss

\section{REFERENCES}

1. Must A, Spadano J, Coakley E, et al. The disease burden associated with obesity. JAMA 1999; 282(16): 1523-1529.

2. Lean ME, Han TS, Seidell JC. Impairment of health and quality of life using new US federal guidelines for the identification of obesity. Arch Intern Med 1999; 159(8): 837-843.

3. National Audit Office. Tackling obesity in England. Report by the Controller and Auditor General. London: The Stationery Office, 2001.

4. Counterweight Project Team. The influence of body mass index on number of visits to general practitioners in the UK. Obes Res 2005; 13: $1442-1449$.

5. Counterweight Project Team. Impact of obesity on drug prescribing in primary care. Br J Gen Pract 2005; 55(519): 743-749.

6. The Information Centre for Health and Social Care. Health survey for England 2004. Updating of trend tables to include 2004 data. Leeds: The Information Centre for Health and Social Care, 2005.

7. Scottish Executive. Scottish health survey: a summary of findings (2003). http://www.scotland.gov.uk/Resource/Doc/924/0019811.pdf (accessed 10 Jul 2008).

8. Norman JE, Bild D, Lewis CE, et al. The impact of weight change on cardiovascular disease risk factors in young black and white adults: the CARDIA study Int J Obes Relat Metab Disord 2003; 27(3): 369-376.

9. Knowler WC, Barrett-Connor E, Fowler SE, et al. Reduction in the incidence of type 2 diabetes with lifestyle intervention or metformin. $N$ Engl J Med 2002; 346(6): 393-403.

10. Tuomilehto J, Lindström J, Eriksson J, et al. Prevention of type 2 diabetes mellitus by changes in lifestyle among subjects with impaired glucose tolerance. N Engl J Med 2001; 344(18): 1343-1349.

11. National Heart, Lung and Blood Institute. The practical guide. identification, evaluation and treatment of overweight and obesity in adults. Bethesda, MD: National Institute of Health, 1998.

12. Broom J, Avenell A, Aucott L, et al. Systematic review of the long term outcomes of the treatments for obesity and implication for health improvement and the economic consequences for the National Health Service. Health Technol Assess 2004; 8(21): iii-iv, 1-182.

13. Health Development Agency. The management of obesity and overweight: an analysis of reviews of diet, physical activity and behavioural approaches. London: Health Development Agency, 2003.

14. British Cardiac Society; British Hypertension Society; Diabetes UK; HEART UK; Primary Care Cardiovascular Society; Stroke Association. JBS 2: Joint British Societies guidelines on prevention of cardiovascular disease in clinical practice. Heart 2005; 91(Suppl 5): v1-52.

15. Hiddink GJ, Hautvast JG, Van Woerkum CM, et al. Nutrition guidance by primary-care physicians: perceived barriers and low involvement. Eur J Clin Nutr 1995; 49(11): 842-851.

16. Moore H, Summerbell CD, Greenwood DC, et al. Improving the management of obesity in primary care: cluster randomised trial. $B M$ J 2003; 327(7423): 1085-1088.

17. Counterweight Project Team. A new evidence-based model for weight management in primary care: the Counterweight Programme. J Hum Nutr Diet 2004; 17(3): 191-208.

18. Counterweight Project Team. Empowering primary care to tackle the obesity epidemic: the Counterweight Programme. Eur J Clin Nutr 2005; 59(Suppl 1): S93-101.

19. Teeley KH, Lowe JM, Beal J, et al. Incorporating quality improvement concepts and practice into a community health nursing course. INurs Educ 2006; 45(2): 86-90.

20. World Health Organization. The world health report 2000 - Health systems: improving performance. Geneva: World Health Organization, 2000

21. Prochaska JO, DiClemente CC, Norcross JC. In search of how people change: applications to addictive behaviours. Am Psychol 1992; 47(9): 1102-1114

22. Carstairs V, Morris R. Deprivation and health in Scotland. Aberdeen: Aberdeen University Press, 1991.

23. Jarman B. Identification of underprivileged areas. Br Med J (Clin Res Ed) 1983; 286(6379): 1705-1709.

24. Counterweight Project Team. Current approaches to obesity management in UK Primary Care: the Counterweight Programme. J Hum Nutr Diet 2004; 17(3): 193-190.

25. Scottish Intercollegiate Guidelines Network. Obesity in Scotland: integrating prevention with weight management. Edinburgh: Scottish Intercollegial Guidelines Network, 1996.

26. Hans TS, Richmond P, Avenell A, et al. Waist circumference reduction and cardiovascular benefits during weight loss in women. Int J Obes Relat Metab Disord 1997; 21(2): 127-134.

27. National Institute for Health and Clinical Excellence. CG43 Obesity: Full guideline. http://www.nice.org.uk/guidance/CG43/guidance accessed 9 Jul 2008).

28. Counterweight Project Team. Influence of body mass index on prescribing costs and potential cost savings of a weight management programme in primary care. J Health Serv Res Policy 2008; 13(3): 158-166.

29. Counterweight Project Team. An economic evaluation of the Counterweight Programme in the United Kingdom. Circulation 2007, 116: II_822. 